\title{
POSIÇÕES DE SUJEITO A PARTIR DA LEITURA E ANÁLISE DO TEXTO NA ESCOLA
}

\author{
Regina Maria Varini Mutti
}

\begin{abstract}
RESUMO: L'approche discursive de la lecture et l'analyse du texte sont présentées dans cet article comme une façon de faire les élèves mieux connaître le fonctionnement du langage dans la societé à laquelle ils appartiennent. Cela fait travailler, d'une part, des thématiques discursives importantes et la position du sujet défendue par l'auteur, et, de l'autre, l'apparition de la position contradictoire et la définition de la position personnelle de l'élève.
\end{abstract}

PALAVRAS-CHAVE: discurso, posições de sujeito, leitura e análise de textos, ensino

Educar o jovem para a cidadania, a partir do ensino de Língua Portuguesa na escola, é um desafio que reconhecemos. Nesse sentido, descrendo de receitas infalíveis para enfrentá-lo, buscamos encará-lo como tema a ser constantemente submetido à investigação, confrontando teoria e prática no próprio currículo escolar.

A Análise do Discurso, através da noção de posições de sujeito desenvolvidas por M. Pêcheux (1978), consiste num referencial teórico profícuo para serem pensadas as diferentes modalidades de interações entre protagonistas de discurso no interior da instituição escolar e, em especial, as que se relacionam ao trabalho com textos nas aulas de português, muitas vezes esvaziadas do seu verdadeiro sentido educativo de participação do educando na vida social, melhor conhecendo o funcionamento da linguagem nessa instância.

Nessa linha, mais especificamente, salienta-se a questão da autoria como uma função do sujeito (ORLANDI, 1988). A autora considera que o autor identifica-se com o princípio de agrupamento do discurso, unidade e origem de suas significações. Essa função é assumida pelo $e u$ enquanto produtor de linguagem, conferindo coerência ao discurso, levando em conta as convenções sociais relativas ao uso da linguagem. É essa a forma-sujeito determinada pelas nossas formações sociais, enquadrada na modalidade jurídica de assujeitamento, pela qual é dada ao sujeito autonomia e, concomitantemente, lhe é cobrada responsabilidade pelo seu dizer. Isso funciona a partir dos esquecimentos, pelo sujeito, das determinações exteriores que sofre, tendo a ilusão de que é ele a fonte de seu discurso (PÊCHEUX, 1988).

Compreende-se, então, a partir da enunciação, segundo aponta Orlandi, a coexistência dos seres empíricos - escritor e leitor - das posições de sujeito-enunciador e de sujeito-autor, com seus correspondentes sujeito-destinatário e sujeito-leitor. Nesse processo, o autor apaga $\mathrm{o}$ sujeito enunciador, causando um efeito de individualidade, mas evidencia, no seu discurso, os enunciados determinados socialmente, referentes ao sujeito-enunciador, manifestando posição de sujeito, sob ilusão de autoria pura desse discurso.

Da maneira como enfocamos a prática pedagógica de leitura e análise de textos, neste artigo, professor e aluno envolvem-se num trabalho de linguagem centrado no texto em estudo,

Regina Maria Varini Mutti é professora da Faculdade de Educação da UFRGS. 
que é compreendido como portador de discursos que são analisados, tendo em vista um processo de reflexão que resulta na constituição de posicionamentos pessoais, estabelecendo-se toda uma dinâmica discursiva da qual o aluno participa ativamente, ocupando o lugar de sujeito-leitor.

Para ajudar os alunos a formar opinião a partir dos discursos que estruturam a vida social, para dela participarem dando sua contribuição, acreditamos ser necessário, primeiramente, provocar-lhes o interesse de discutir problemáticas do contexto, com as quais eles tenham algum tipo de contato e que, de alguma forma, os sensibilizem. Essas problemáticas lhes são, então, reapresentadas em textos curtos para leitura e análise dos temas e pontos-de-vista de sujeitos manifestados, em cuja linguagem é preciso descobri-los e com os quais é possível dialogar, construindo novas significações. Estas passarão a integrar a memória discursiva do leitor.

Reiterando o que diz Orlandi, "o discurso é uma das instâncias materiais (concretas) dessa relação entre linguagem/pensamento/mundo" (1996, p.12). Nessa perspectiva, ao constituírem-se como sujeitos-leitores, os alunos produzem sentidos a partir da interpretação historicamente possível, dinamizando o que e como pensar. Acreditamos ver aqui relação com a psicologia dialética (RIEGEL, 1975), no sentido em que esta concebe a cognição como uma construção contínua e dinâmica de significações pelo indivíduo, frente às contingências que o determinam, caracterizadas como contradições, obrigando-o a escolhas e conseqüentes ressignificações.

A realização desse tipo de proposta na sala de aula requer uma intenção pedagógica clara e sistemática, de tal forma que mereça a adesão da classe, tornando-se um projeto comum que pressupõe a participação comprometida de todo o grupo de alunos e de seu professor.

$\mathrm{O}$ fato de existir um projeto como atividade central tem a vantagem de dar maior funcionalidade à produção a ele ligada, causando um efeito de sentido - bastante salutar - de se estar extrapolando os limites negativos do discurso pedagógico, a partir do resgate de seu sentido positivo, estreitando-se o compromisso individual e do grupo com a dimensão do aprender, do estudo da linguagem. Aqui lembramos a proposta pedagógica de Geraldi (1991), com a qual nos identificamos.

No referido projeto, embora permaneça a especificidade dos diferentes papéis, de professor e de alunos, cria-se outro sentido - de simetria e cumplicidade - resultante do fato de que ambos - professor e alunos - são igualmente leitores, voltados para a análise de problemáticas de uma sociedade da qual ambos são membros e se sentem como cidadãos . Falando desse lugar, todos têm direito de construir sua própria interpretação, assumindo posições de concordância ou de discordância frente aos sentidos percebidos, produzindo, assim, os inevitáveis deslocamentos, condizentes com a própria natureza constitutiva da interpretação.

Dessacraliza-se, também, a palavra impressa como verdade absoluta, uma vez que o autor do texto passa a ser visto como aquele que faz um pronunciamento sobre a realidade, enquadrando-se nas convenções consonantes com essa função, manifestando, assim, o seu ponto de vista, e, nesse percurso, se encontram outras vozes implícitas, silenciadas, latentes, como contingência imprescindível do processo de produção de sentidos em que consiste a autoria.

Professor e alunos, bem como os colegas entre si, acentua Orlandi (1988), tendo diferentes histórias como leitores, diferem em suas leituras, e essas diferenças devem ser respeitadas e incentivadas. Não obstante, cabe ao professor um cuidadoso trabalho preliminar de planejamento, que supõe a sua própria análise discursiva do texto escolhido para trabalhar com seus alunos, bem como dos procedimentos pedagógicos que empregará nesse intuito.

A opção pela perspectiva do discurso exige análise aprofundada a partir do texto, visto como intradiscurso, de modo que permita chegar às posições de sujeito a partir de pistas lingüísticas, mediante todo um processo que não se desvenda facilmente e que requer o 
estabelecimento de relações entre o lingüístico e suas condições de produção, no nível ideológico, interdiscursivo (COURTINE, 1981).

Sistematizando o projeto direcionado à cidadania, o planejamento preliminar requer do professor o estabelecimento de alguns critérios para determinação do conjunto de textos para leitura e análise, de modo que estes representem recortes discursivos de relevância para a abordagem pretendida. Assim, por exemplo, a definição de campos como - o político, o educacional, o econômico - referindo problemáticas importantes que ocorrem nos contextos municipal, estadual e nacional - relacionados a textos de vários gêneros: crônica, reportagem, propaganda, letra de música, fábula, entrevista são elementos levados em conta de modo a dar uma certa unidade e, ao mesmo tempo, diversidade ao recorte que se pretende montar. Esses textos podem ser extraídos de jornais, revistas, obras diversas, e a escolha dos mesmos pode ser feita também pelos alunos, durante o processo que pode ter a extensão do semestre ou do ano letivo.

Vejamos alguns aspectos do trabalho com o texto "Literatura para o Povo", integrante de pesquisa que fizemos com alunos da segunda série do $2^{\circ} \mathrm{Grau}$, em escolas públicas de Porto Alegre (MUTTI,1993). Esse ensaio jornalístico, apresentado aos alunos na terceira sessão do projeto de leitura e análise de textos, foi escolhido com o propósito de desencadear a reflexão sobre a problemática do acesso à educação em nosso país. Levantando dados sobre a enunciação, foi indicada a data e o local de publicação do texto, o nome do jornal e do autor. Sobre o autor, conforme indicação presente no próprio texto, salientamos que é professor universitário e escritor, membro da Academia Brasileira de Letras; acrescentamos o fato de ser ele especialista de nome reconhecido na área sobre a qual se pronuncia: a literatura e o ensino desta.

Conforme análise prévia do professor, encontramos no texto em questão a manifestação de discursos, evidenciando-se posições de sujeito diversas; o sujeito-autor está assumindo posição, refutando a tese da posição oposta, de que se deva levar a literatura ao povo.

Remetendo ao interdiscurso, tendo em vista o domínio da memória e o da atualidade, verificamos rumores de vozes concernentes à polêmica em torno do tema do acesso do povo à literatura. A idéia de democratização da literatura, buscando expandi-la para a população mais ampla, tem mobilizado profissionais da área e políticos que se colocam contra ou a favor desse tema. Esse debate, que envolve posições antagônicas, evidencia a dimensão política do ensino da literatura, junto à visão técnica do mesmo. É nesse quadro que surge a manifestação do autor nos veículos de comunicação de massa, escrevendo o presente texto, cuja atualidade se mantém, apesar de ter sido publicado há mais de uma década.

Nesse sentido, podemos apontar, como invariante interdiscursiva, a literatura vista como um bem cultural cuja fruição se restringe às elites cultas da nação, minoritárias na sociedade brasileira, condição esta que não pode sofrer nenhuma alteração, merecendo censura e desprezo aqueles que pretendem alterá-la..

Examinando o intradiscurso, constatamos diferentes vozes, representando posições de sujeito opostas. Procuramos, então, evidenciar a vinculação entre o saber interdiscursivo representante da posição assumida pelo enunciador, a partir do modo como aparece na superfície lingüística. Verificamos que o autor destaca enfaticamente alguns elementos do saber que atribui à voz refutada, expondo-os de modo a fragilizá-los, produzindo um efeito de indignação. Logo após, corrige a estultice proferida pela voz contrária, causando um efeito didático, colocando-se na posição daquele que do alto ensina o óbvio àqueles que o ignoram, e assim reafirma saberes concernentes à posição de sujeito que representa. Então, resume anaforicamente o que diz a voz dos outros através de pronomes coesivos, enfatizando a voz que assume como sua, fechando o sentido com um efeito de retificação. Vejamos:

(1) "Literatura para o povo. A gente ouve de vez em quando esta declaração, às vezes de maneira enfática, sobre que a literatura deve ser feita para o povo. Há pouco escutei, num congresso de literatura, a afirmação de que a crítica deve existir para o povo, que devem os 
suplementos literários voltar-se para o povo e outras frases quejandas. Ora, isso não passa de uma grande demagogia."

(2) "Que é o povo? Que idéia de povo está por trás dessa assertiva? Assim, em primeiro lugar eu precisaria saber que é que se entende por povo nos contextos referidos. Se por povo se entende ali pela massa, pela grande maioria da população, então a essa gente não há que se oferecer literatura, crítica literária, suplementos cheios de colaborações de poesia, ficção e crítica. O que deseja essa gente é comida, sapato, casa para morar."

Assim, vejamos:

Isso (que $\mathrm{P}$ ) é $\mathrm{X}$

$\mathrm{O}$

$\mathrm{P}=$ saber atribuído à voz refutada $\quad \mathrm{X}=$ saber defendido pelo autor

(1) ...isso (P) ...que a literatura deve ser feita para o povo... que a crítica deve existir para o povo...que devem os suplementos literários voltar-se para o povo...) élnão passa de (X) uma grande demagogia

(2) O que deseja essa gente (a idéia de povo que está por trás dessa assertiva... nos contextos referidos...) é $(X)$ comida, sapato, casa para morar

Remetendo ao interdiscurso, considera-se, que na própria constituição da formação discursiva, os saberes opostos se confrontam, representando posições antagônicas; procuramos, então, representá-los, montando a contradição:

(x) "a literatura deve ser para o povo... a crítica deve existir para o povo..."

(y) a literatura não deve ser para o povo

Como podemos constatar, o tema defendido pelo autor (X) se situa em (y), e o saber refutado $(\mathrm{P})$, em (x). Assim, o autor nega o que afirma a voz contrária, argumentando que o povo não precisa de literatura, mas de "comida, sapato, casa para morar". O efeito de sentido resultante desse jogo é a desqualificação do saber refutado e a evidência do saber que defende como algo de óbvio. Mais adiante vamos encontrar no intradiscurso que a participação do povo, no que tange à literatura, dá-se apenas como inspiração, como personagem.

No entanto, a voz minimizada neste discurso acaba desvelando outro sentido possível, relativo à questão da educação, indicada pelo autor como elemento que falta ao povo para que possa fruir a literatura. Nessa direção, fica excluída a contribuição da literatura para a instrução das pessoas, a qual deveria começar desde cedo, na escola básica, contando com a literatura no currículo. E, ainda, que a educação permanente das pessoas em geral, mesmo fora do sistema escolar, possa prescindir do contato com a literatura, dentre as várias maneiras com que este possa ser realizado. Assim, implicitamente, abre-se espaço para que falem possíveis argumentos a favor da tese refutada, que representem saberes vinculados à posição de sujeito dominado. Ao mesmo tempo, fica demonstrada a heterogeneidade de vozes referentes a pontos de vista distintos, coexistentes, confrontados no discurso.

Ao fazer sua própria análise a partir do texto em questão, é natural que o professor construa sua posição, como sujeito-leitor, enquanto que também assume a posição representada pela proposta pedagógica que defende, inserindo-se numa formação discursiva pedagógica que postula a importância de o aluno tornar-se um leitor ativo, formando seus próprios pontos-devista sobre o modo como os sentidos vão-se formando, na vida em sociedade, pela ação de sujeitos. Pois bem, a segunda condição deve prevalecer sobre a primeira, de início, de modo que o professor não inculque no aluno a posição que já assumiu, deixando-o livre para construir seus próprios sentidos.

No entanto, torna-se importante educar o olhar do aluno, mediando o diálogo deste com o que é dito, não no sentido de impossibilitar ou censurar a interpretação, mas, ao contrário, orientando-o no sentido de que explore cuidadosamente a linguagem evidenciada no texto, informe-se sobre as condições de enunciação, extrapolando o texto no sentido de vincular o que é dito a ideologias vigentes no contexto. É necessário estimular o aluno a descobrir sentidos implícitos, bem como a inferir o que diriam aqueles que discordam dos temas 
defendidos no texto, representantes da posição contraditória. Prevendo-se atividades escritas e orais, o aluno deve ser solicitado a opinar, concordando ou discordando do tema defendido pelo autor, assumindo ele próprio sua posição. Isto feito, poderá o professor também explicitar sua própria opinião, estabelecendo-se debate no grupo.

Eis a análise que fizeram alguns alunos na experiência a que nos referimos:

* Pergunta (do professor): Tendo em vista o que o autor afirma no terceiro. parágrafo, qual a justificativa que ele dá para a sua afirmação?

* Resposta (do aluno): Este povo quer comida, sapato, casa para morar; ao povo, ali referido, não há o que se oferecer, ou seja, literatura, crítica literária, poesia, ficção não são feitos para o povo.

*Pergunta: Conforme o autor, como consideram o povo as pessoas que pensam de modo diferente dele?

*Resposta : Como peças de articulação e não pessoas que têm necessidades e direitos.

* Pergunta: Como o autor considera o povo (condições, necessidades, direitos...)?

*Resposta: Radical, pois, pelo fato de que o povo se encontra com outras necessidades mais importantes que a literatura, não quer dizer que o povo não possa se identificar com ela e apreciá-la.

*Pergunta: Consideras a posição do autor frente à questão da literatura favorável ao povo ou não?

*Resposta: Não, pois, de certa forma, ele tenta privar o povo da literatura. É um modo de tentar nos bitolar e reduzir ainda mais o povo.

*Pergunta: Sobre a questão da literatura para o povo, qual é a tua posição?

* Resposta: A literatura deve ter um alcance tanto para o povo quanto para as outras classes sociais, ou seja, estar ao alcance de todos

Podemos entender que o jovem identifica o tema articulado pelo autor, conseguindo perceber a posição de sujeito oposta, embora esta se encontre encoberta nos meandros da argumentação desenvolvida pelo autor em prol da tese que defende, em aliança com uma posição de sujeito que postula que a literatura se reserva apenas às elites cultas. Ao colocar entre aspas a palavra povo, o aluno revela seu estranhamento à carga pejorativa que acompanha esse termo no discurso do autor, implicitando que, para ele, a palavra povo é mais abrangente. Manifestando sua opinião pessoal, deixa clara sua discordância ao posicionamento do autor, descobrindo que este "de certa forma, tenta privar o povo da literatura... reduz ainda mais o povo... tenta nos bitolar", demonstrando sentir-se também atingido, como leitor e participante do universo povo. Optando pela posição contraditória que foi capaz de sincronizar a posição atribuída ao autor, o jovem justifica-se trazendo à tona o discurso da igualdade de direitos para todos, incluindo o acesso à literatura como um direito de todos. Portanto, o jovem inclina-se para a posição que o autor refuta, situada no pólo (x) da contradição.

Mas há também aqueles alunos que, embora situando basicamente a tese que o autor defende, não conseguiram sincronizar os pontos de vista opostos representados na contradição. Isso determinou que só conseguissem repetir e reforçar o ponto de vista do autor, sem deslocar sentidos de um modo divergente. Como exemplo, apontamos o que diz este aluno: entende que para o autor "a literatura não deve mudar, e sim o povo deve mudar", pois "o povo, no sentido da maioria da população, vive com fome, pobreza, sem moradia, sem direitos". E as pessoas que pensam de modo diferente do autor consideram o povo "como um conjunto de pessoas que vive muito bem, alegre nas suas casas, gente simples que deve ter direito à literatura". "Minha posição é que a literatura deve ficar como está, mas a população pobre deve receber infraestrutura (comida, educação etc.) para poder apreciar a literatura". Percebe-se que o aluno teve dificuldades, desde a identificação do tema, perdendo-se no meio da própria estratégia argumentativa empregada pelo autor, o qual desvia a realidade de sua posição e aceita o fato do distanciamento de muitas pessoas da literatura, através da denúncia da miséria em que vive o povo. Essa atitude de denúncia é apoiada pelo aluno, que se comove com a situação do povo. 
Sugere-se que o aluno foi persuadido pela argumentação do autor, mas, de uma certa forma, dando-se conta disso, pois, ao opinar sobre a linguagem usada pelo autor não foi "clara"..., deixando transparecer certa indecisão e contradição... Não se sabe a verdadeira idéia do autor até que se leia o último parágrafo. Esse fato parece explicar também a ingenuidade da resposta do jovem à questão em que deveria imaginar o que diriam as pessoas que discordam do ponto de vista do autor sobre a literatura para o povo.

Uma comparação entre os desempenhos dos dois jovens aqui referidos parece indicar que o primeiro atendeu melhor à solicitação de remeter ao contraditório, descobrir sentidos implícitos presentes na proposta pedagógica do projeto de leitura.

Ao final do ano letivo, quando os jovens tiveram de trazer à memória as posições de sujeito representadas nos textos lidos e analisados, bem como a sua própria posição, dentre os que escolheram pronunciar-se sobre "Literatura para o povo", pudemos constatar que: grande parte reteve a temática da indignação perante o sofrimento do povo, privado das necessidades mais básicas do ser humano, que o autor acentuou no seu texto, indicando sua solidariedadde com o povo explorado; da mesma forma, guardaram na memória o ponto de vista do autor, concordando com ele ("primeiro alimentar o povo, e depois sim, dar-lhe literatura"). Mas também houve alguns que registraram a posição de sujeito oposta à do autor e afirmaram sua discordância: “...o problema não é que não adianta dar cultura para um povo que não tem comida; cultura e educação também são necessidades, junto com a comida; ... o povo também tem o direito de desfrutar das obras literárias".

Refletindo sobre os pontos-de-vista manifestados pelos jovens, acreditamos que as adesões ao autor, embora consistindo em uma posição conservadora, também representaram um tipo de ressignificação, pois incidem, mais exatamente, sobre a denúncia das privações que sofre o povo, incluindo a inacessibilidade da literatura, lamentando esse fato. Em menor número, os jovens que discordaram da posição assumida pelo autor conseguiram visualizar a imobilidade dessa posição de sujeito, vislumbrando a necessidade, ou mesmo a possibilidade, de mudanças no enfoque da problemática constatada, de modo que não se postergue indefinidamente a acesso do povo à literatura, devido às carências que sofre.

Eis o registro do pronunciamento de alguns alunos, defrontados com a formação discursiva pedagógica representada na proposta com a qual interagiram:

... Muitas vezes não nos damos o trabalho de pensar e formular opiniões... Parei para refletir sobre uns assuntos que não tinha parado antes. ... O meu modo de raciocinar acho que continua o mesmo. O que mudaram foram as informações que agora posso utilizar nas próximas leituras como fonte de comparação. Sempre tive minha própria opinião formada, mas meu raciocínio melhorou muito, pois não enxergava certas coisas que estavam a meu lado. ... Eu acho que não adianta só ter as opiniões, mas sim estas devem ser refletidas a partir da observação de outros pontos de vista.

Já no texto a seguir, o jovem, ao assumir posição de sujeito, retrata o quanto the chamou atenção a linguagem do autor, de cujo estilo parece fazer uma paródia:

$\mathrm{O}$ texto é interessante, bom de ler e possui uma lógica no desenvolvimento do raciocínio bem clara - o que já se esperava de um professor e membro da ACL. Mas, de uma certa maneira, não gostei muito do que ele colocou. Não sei se estou sendo justo, mas o autor pareceu-me um pouco pedante.

Por que tenho a coragem de afirmar isso? Primeiro, porque eu tenho o direito. Ele generalizou o povo brasileiro como sendo a pobreza. Não é apenas isso. Se ele não faz parte do povo, o que está explícito no texto, ele faz parte do quê? Da elite? Elite também é povo.

$\mathrm{O}$ autor também coloca a falta de necessidade de cultura em quem não possui condições de uma vida digna. O simples fato de eu estar com fome, com frio, não impede que eu tenha interesse em escutar uma música, em ver a arte, ler. É lógico que antes é preciso dar comida, saúde etc...Mas como Arnaldo Antunes diz: "a gente não quer só comida / a gente quer comida, diversão e arte" . 


\section{ANEXO \\ ESCANEAR - texto "Literatura para o povo"}

\section{BIBLIOGRAFIA}

COURTINE, J.J. Analyse du discours politique; le discours communiste adressé aux chrétiens. Langages, n. 62, jun. 1981.

COUTINHO, A. Literatura para o povo. Última Hora, Rio de Janeiro, jan.1981.

GERALDI, João W. O texto na sala de aula. In: Leitura e produção. 7 ed. Cascavel, ASSOESTE, 1991.

MUTTI, Regina M. V. Do texto ao discurso no ensino crítico de língua portuguesa no segundo grau e o desenvolvimento cognitivo do adolescente. Porto Alegre, Tese de Doutorado. Curso de Pós-Graduação em Letras, PUCRS, 1993.

ORLANDI, Eni P. Discurso e Leitura. Campinas, Cortez, 1988. Interpretação; autoria, leitura e efeitos do trabalho simbólico. Petrópolis, Vozes, 1996.

PÊCHEUX, M. Hacia el análisis automático del discurso. Madrid, Gredos, 1978. Semântica e discurso; uma crítica à afirmação do óbvio. Campinas, UNICAMP, 1988. . O discurso; estrutura ou acontecimento. Campinas, Pontes, 1990.

RIEGEL, K. The dialectics of human development. American Psychologist, p. 689-700, oct.1976. 